\title{
Surface Humidity Changes in Different Temporal Scales
}

\author{
Igor Zurbenko, Ming Luo* \\ Department of Epidemiology and Biostatistics, State University of New York at Albany, Rensselaer, USA \\ Email:
}

Received 18 March 2015; accepted 30 May 2015; published 2 June 2015

Copyright (C) 2015 by authors and Scientific Research Publishing Inc.

This work is licensed under the Creative Commons Attribution International License (CC BY). http://creativecommons.org/licenses/by/4.0/

cc) (i) Open Access

\begin{abstract}
As the key driven factor of hydrological cycles and global energy transfer processes, water vapour in the atmosphere is important for observing and understanding climatic system changes. In this study, we utilized the multi-dimensional Kolmogorov-Zurbenko filter (KZ filter) to assimilate a near-global high-resolution (monthly $1^{\circ} \times 1^{\circ}$ grid) humidity climate observation database that provided consistent humidity estimates from 1973 onwards; then we examined the global humidity movements based on different temporal scales that separated out according to the average spectral features of specific humidity data. Humidity climate components were restored with KZ filters to represent the long-term trends and El Niño-like interannual movements. Movies of thermal maps based on these two climate components were used to visualize the water vapour fluctuation patterns over the Earth. Current results suggest that increases in water vapour are found over a large part of the oceans and the land of Eurasia, and the most confirmed increasing pattern is over the south part of North Atlantic and around the India subcontinent; meanwhile, the surface moisture levels over lands of south hemisphere are becoming less.
\end{abstract}

\section{Keywords}

Specific Humidity Climate, El Niño-Like Movement, Long-Term Trend, KZ Filters, Spatial Pattern, Temporal Scales, High Resolution, Visualization

\section{Introduction}

Given the importance of water vapor to global ecological system, atmospheric circulation and energy budget [1] [2], a high-resolution database for monitoring the global surface humidity changes would be of high value. It is also fundamental in quantifying the incompletely understood changes of global climate. Recently published

${ }^{*}$ Corresponding author. 
HadISDH database [3] provides annually updated in situ observations-only humidity data covered most of the land surface with $5^{\circ} \times 5^{\circ}$ grids. Surface humidity anomalies data HadCRUH, which covered both worldwide lands and oceans for the time period of 1973 to 2003, was also in low resolution $\left(5^{\circ} \times 5^{\circ}\right)$ [4]. Related satellite and radiosonde datasets are regional in focus or aren't suitable for detecting trends of surface water vapor levels on decadal scales [5]. Although several reanalysis datasets are available for weather and climate analysis [6] [7], observation data are still useful for validation or diagnosis purpose. Due to the vary problems for existing humidity datasets, the availability of multiple methodologically independent estimates is crucial to understanding the structural uncertainties of analyses results.

In this paper, we propose to construct a near-global high-resolution $\left(1^{\circ} \times 1^{\circ}\right)$ in situ actual observation value based humidity database that covers both land and marine surface. We may need to compromise data accuracy in areas with low observation density, but it will provide us new insights with detailed spatial patterns of worldwide humidity movements on the high resolution maps. Given the high-accuracy feature of Kolmogorov-Zurbenko filters (KZ filters), we can reconstruct useful information from observations mixed with noise and mistakes [8]-[12]. We will show that, with the help of some basic quality control measurements, this approach will provide satisfied results for a wide of study purposes.

Water vapor movements contain scales that behave independently in time and space, and therefore should be separated and examined independently. As a crucial step for further analyses, we decomposed the temporal variations into components of different time scales, corresponding to their spectral energy distributions. The generated components represent water vapor variations with long-term ( $>9$ years) and El Niño-like (2 to 6 years) interannual time scales. This strategy enabled us to visualize global humidity movements in a clear and intuitive way. It also enables us to provide essentially higher coefficient of total explanation by keeping different sources separately compared with traditional single variable explanation. Their spatial patterns therefore can be evaluated through the movie of global water vapor components.

The following sections are structured as follows. Section 2 describes the creation of the high-resolution humidity actual values dataset. Section 3 introduces the method to identify and separate out humidity climate components of different scales. Section 4 focuses on the leading features of this database, including linear trends of recent decades, spatial-temporal patterns for long-term and interannual fluctuations. In Section 5, we discuss the rationale of the study design and compare with existing humidity studies, and try to explain related findings with atmospheric circulation patterns.

\section{Creation of the Database}

\subsection{Selected Humidity Variable}

There are a number of different measures used to describe the amount of water vapour in the atmosphere. For example, relative humidity ( $\mathrm{RH})$, dew point temperature (Td), vapour pressure (e), etc., had been widely used in different studies [13]-[16]. Here we chose specific humidity (SH) as the studied humidity variable.

Specific humidity, aka mass concentration or moisture content, is the ratio of the mass of water vapor in a given parcel to the total mass of air in the parcel. It is measured in $\mathrm{g} / \mathrm{kg}(\mathrm{or} \mathrm{kg} / \mathrm{kg}$ ) and can be described thus:

$$
q=m_{v} /\left(m_{v}+m_{a}\right)
$$

In this definition, the numerator $m_{v}$ is the mass of water vapour in $\mathrm{g}$ (or $\mathrm{kg}$ ), while the denominator $\left(m_{v}+m_{a}\right)$ is the mass of water vapour plus the mass of dry air in $\mathrm{kg}$ [17]. The reading of specific humidity remains constant as long as moisture is not added or taken away from a given mass, whereas relative humidity, dew point, and absolute humidity changes with temperature and air pressure fluctuations. Movement of relative humidity and dew point is more complicated because the essential change of moisture content is affected by variations in other environmental factors.

We followed the conversion algorithms used in HadCRUH to convert dew point records to specific humidity values. Please refer literature [4] for the formulae. Additional variables, i.e. dew point, relative humidity, air temperature, and sea level air pressure are also included in the dataset for the conversion conclusions.

\subsection{Marine and Land Data Sources}

The marine data used in our study were from the International Comprehensive Ocean-Atmosphere Data Set (ICOADS), R2.5 Monthly Summaries and NRT (NCEP Real-time) Marine Observations, Enhanced dataset [13]. 
This database collected metrological records from ships, moored buoys, drifting buoys, and other observing systems, and combined those heterogeneous records to generate the monthly averaged climate fields for $1^{\circ}$ latitude $\times 1^{\circ}$ longitude grids back to the 1960 s. Selected climate variables, including sea-surface temperature, air temperature, specific humidity, and sea-level pressure, as well as related data quality information (standard error, etc.) were extracted as ASCII files and then were transformed as R datasets.

The data source for land surface was the Global Summary of Day (GSOD) data product based on the Integrated Surface Database (ISD) [14]. Temperature, sea-level pressure, station air pressure, and dew point records for more than 20,000 weather stations from around the world were compiled and aggregated as monthly land surface data with a resolution of $1^{\circ}$ latitude $\times 1^{\circ}$ longitude grid, from the 1960s onward. To be consistent with the marine database, climate values were all converted to the International System of Units (SI). To avoid the data gap of ISD in the early 1970s, the initial year of the database is selected as 1973.

\subsection{Data Quality Control}

A suit of tests were applied to exclude physical implausible values, persisted values, and outliers before summarizing and gridding the data. Since both land and marine data source have already undergone some quality control, the affected data is less than $1 \%$ for this step.

When summarized the data, we followed the common used minimum missing value criteria of this field [3][6]. For example, four reporting times per day covering both night and day time, 15 days with data per month, 2 months per season, etc. About $10+\%$ data are excluded based on related rules.

To simplify the calculation and keep actual values in the database, we didn't deduct the climatology normal to take out the bias caused by seasonality. Instead, this kind of bias was evaluated with seasonal scores. As exhibited in Figure 1, summer months are set seasonal scores close to 1, while winter months are close to -1 , and spring/autumn months are around 0 . It shows that, for ocean areas with latitude great than $70^{\circ}$, most records were collected during May to Aug.; while for the oceans around Antarctic, data were mostly recorded in Dec. to Feb. This kind of bias could be amended for most places by smoothing with nearby grids. However, even after spatial interpolation (as described in the next subsection), grid points over sea surface around Antarctic still have highly-biased seasonal scores and therefore are excluded.

\subsection{Spatial Interpolation}

A large part of ocean data comes from "floating" platforms with changing locations. Outside the major ship routes, it is usually hard to find a grid point on the ocean with observations continued over several years. Missing data are prevailing. Fortunately, specific humidity is relatively spatially consistent over hundreds of kilometers [4]

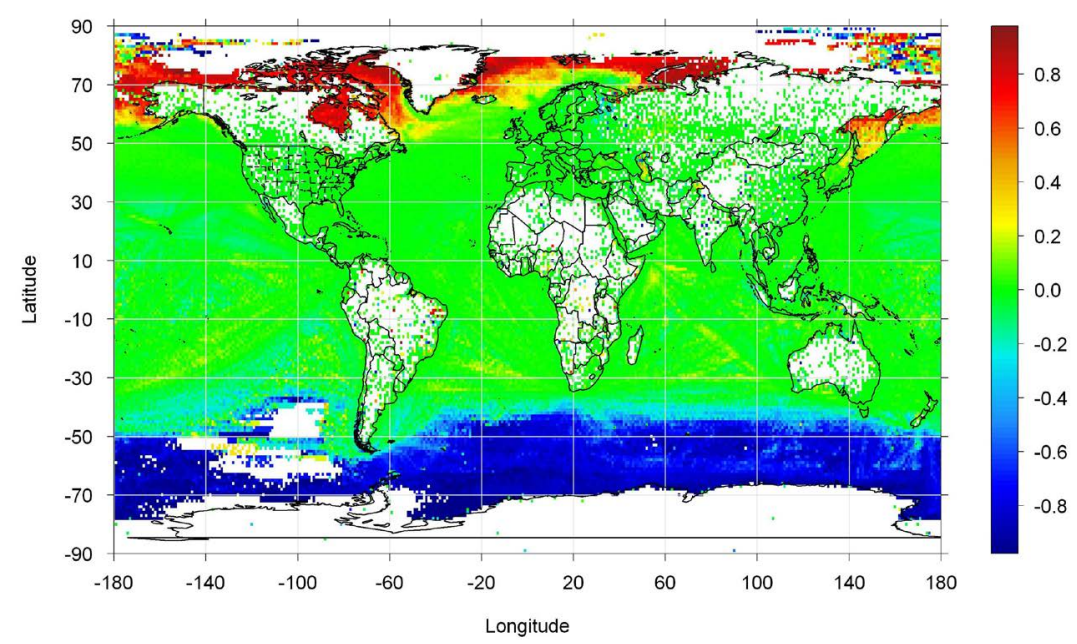

Figure 1. The coverage and seasonal bias of gridded $\left(1^{\circ} \times 1^{\circ}\right)$ specific humidity observations. Blue points are grids with data mostly collected in Dec., Jan., and Feb., while data of red points are mostly collected in Jun., Jul., and Aug. Green points are for grids with data usually collected over the year. 
from the global climate prospective, and most missing could be replaced with nearby data points. As an averaging operation, smoothing would exclude extra uncertainties caused by data mistakes. Moreover, spatial interpolation fills in each grid cell and therefore "add values" to the dataset. It should be taken as an important step of data preparation for both marine and land data.

Hereafter we use the notation $\mathbf{K Z}_{m, k}$ to refer to $\mathrm{KZ}$ filters that iteratively calculating the moving average of $m$ data points $k$ times. We selected $\mathbf{K} \mathbf{Z}_{m}=(3,3), k=4$ to spatially smooth specific humidity and other variables. "Neighbors" under this setting are grids within $4^{\circ}$ latitude or longitude $(444 \mathrm{~km})$. It is in good agreement with the $5^{\circ} \times 5^{\circ}$ grid size in HadCURH and HadISDH. This distance may look vast for humidity in weather analysis, but we will show that it is appropriate for the analysis of global climate phenomena under given conditions.

A snapshot of the spatially smoothed specific humidity data is exhibited in Figure 2. The smoothed data covered more than $95 \%$ of the areas north of $-50^{\circ}$ latitude. It suggests that the coverage of this database is fairly good; but over the oceans around Antarctica, existing data is still not enough to depict a decent climate field. Some areas in Africa, like Congo and Angola, are also deficient in humidity observations. In this plot, heavy moistures are concentrated near the equator of East Pacific and biased to north in this season; Hadley cells between $-30^{\circ}$ and $30^{\circ}$ latitude obviously discriminated itself with other regions in the mid-latitudes, considering the seasonal bias and geographic variations. Such details suggest that the resolution of this dataset is good enough for meaningful visualization and analysis.

\section{Temporal Decomposition of Humidity Data}

Coupled with seasonality of air temperature, specific humidity data usually exhibit strong annual oscillations outside of tropics. Beside this most manifest feature, some other common temporal fluctuations are presented as the average spectrum [9] [18] [19] of humidity variations in Figure 3.

The common spectrum energy can be divided into two groups by the red dash-line in the plot: on the left side, fluctuations in 3.1- to 6.4-year cycle can be attributed to El Niño-like phenomena; while the 9.1- to 12.3-year cycles on the right side could be from long-term climate activities and solar-Earth interactions. Separating these time scales will help us to reveal physical mechanisms and dynamic forces behind humidity movements.

We applied $\mathbf{K} \mathbf{Z}_{29,5}$ to reconstruct the long-term specific humidity component (>8.33 yrs), and filter $\left[\mathbf{K Z}_{11,3}\right.$ (1-KZ $\left.\mathbf{K}_{29,3}\right)$ ] for the El Niño-like component $(<8.33$ yrs). Under such setting, the annual and intra-annual fluctuations were strongly suppressed to less than $0.11 \%$. The most manifested signal caused by seasonality will not mix with the El Niño-like component.

As a validation effort, we randomly selected some grid points and checked their spectrum. All the results clearly indicated that KZ filters separated long-term and El Niño components as desired, and there is no signal leaking for annual and seasonal frequency. As an example, Figure 4 displays a typical time series of specific humidity as well as its long-term and El Niño-like component. The grid cell is at the central of Pacific Ocean,

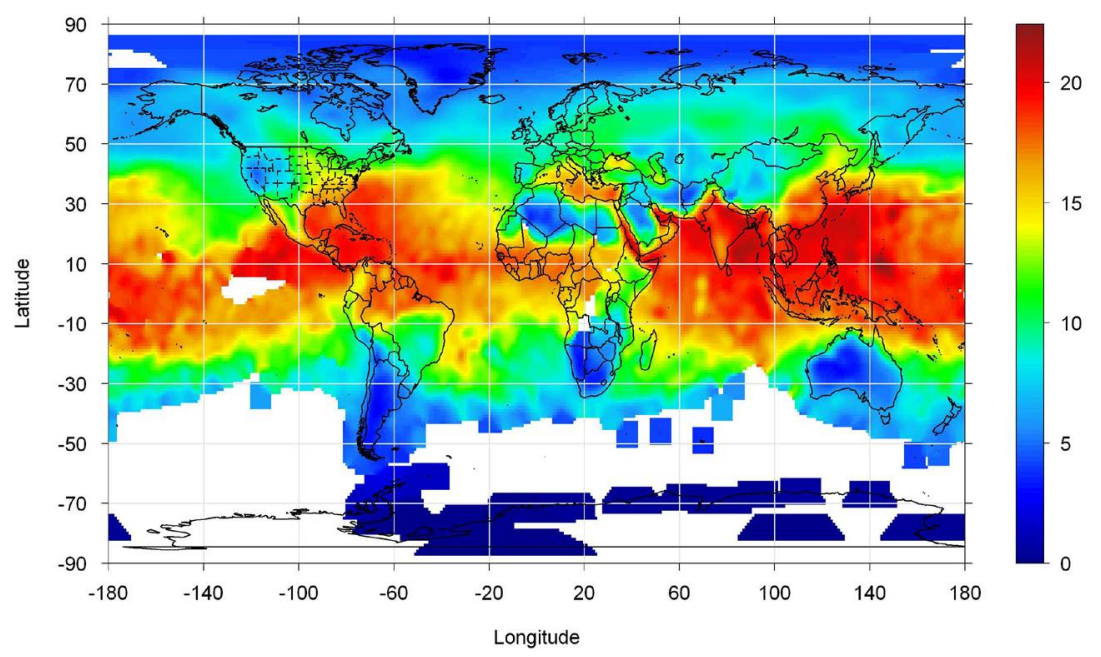

Figure 2. Spatial interpolated global-specific humidity distribution on July 2013. Units are in $\mathrm{g} / \mathrm{kg}$. 


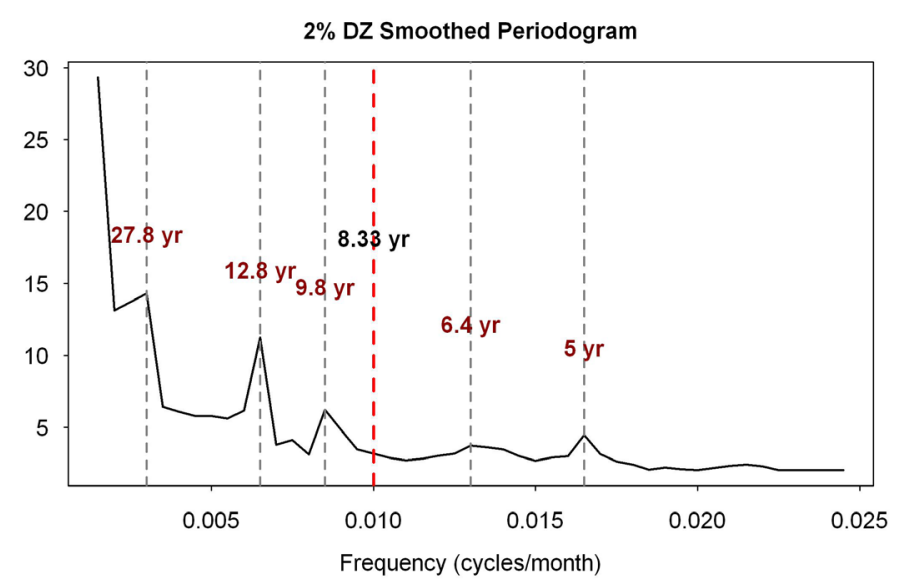

Figure 3. Common frequency components of global specific humidity.
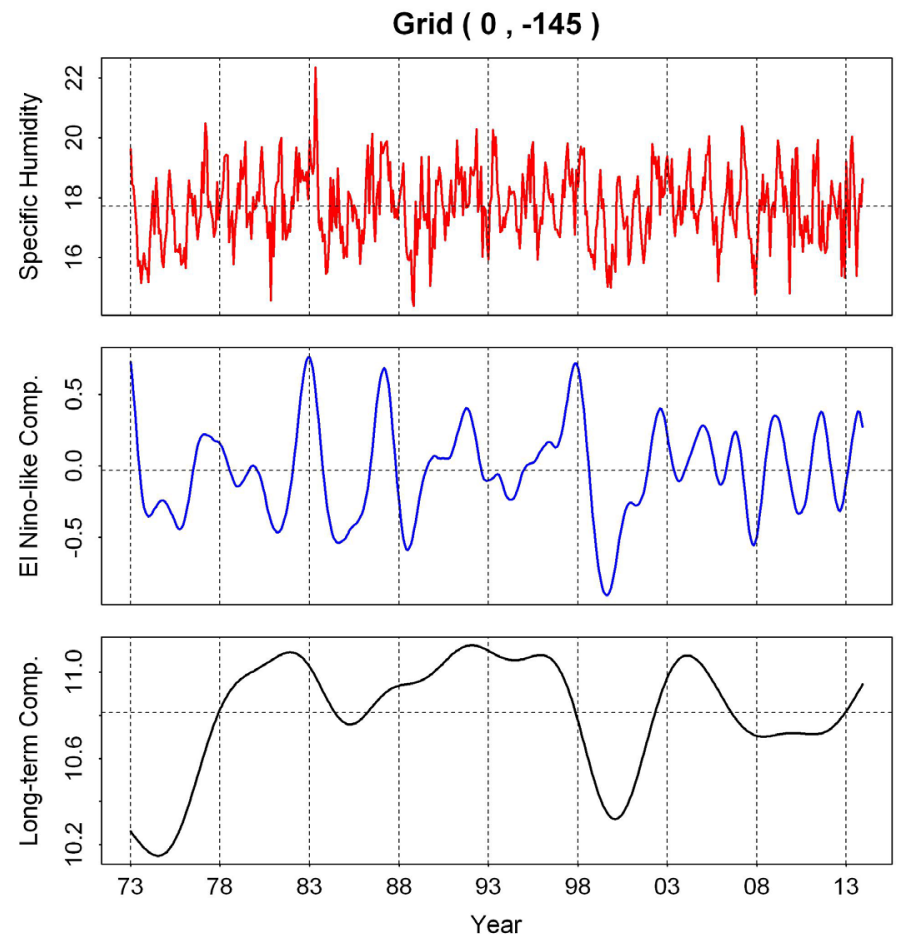

Figure 4. A typical specific humidity time series and its long-term and El Niño-like components. Units are in $\mathrm{g} / \mathrm{kg}$.

latitude $0^{\circ}$ and longitude $-145^{\circ}$. As expected, its El Niño-like component follows closely with the Niño 3.4 index [20]. The potential trend on the time-series plot of the long-term component is obvious when detected with eyes.

\section{Features of the Global-Specific Humidity Database}

To create the humidity database, we gridded all variables on $1^{\circ} \times 1^{\circ}$ grid boxes first; and then smoothed marine and land data, separately. The conversation of specific humidity for land grids was arranged after spatial smoothing to maximize the data coverage. Considering the difference of moisture levels over lands and oceans, the flag for land and marine grids will be kept in the combined near-global humidity database. Meanwhile, the temporal decomposed data components simplified the global humidity movement patterns and therefore will enable us visualize and explore its variation in a clear and intuitive way. 
Next, we will discuss the leading features of this humidity dataset, including spatial pattern of humidity trends, the visualization of long-term and interannual fluctuations.

\subsection{Recent Trends Based on Gridded Data}

We checked the spatial pattern of linear trends for annual humidity means from 1973 to 2012 based on gridded data, as exhibited in Figure 5. Estimation is based on the median of pairwise slopes [21] for each grid point with 30+ year's data. The map is in good agreement with existing works [3] [4] [6] for most locations. Basically, it presents to us a widespread moistening pattern with drying over the subtropical lands, which could be caused by an intensified hydrological cycle over recent years.

The largest increasing moisture pattern is over the North Atlantic, around $0^{\circ}$ to $45^{\circ}$ latitude. There are strong increasing signals on the Pacific Ocean, too. However, they are mixed with several drying patches. A conspicuous drying part is around latitude $15^{\circ}$ and longitude $230^{\circ}$, close to the drying area over Mexico and the Four Corners region of USA. It suggests that the moisture movements on Pacific surface are complicated. Similar on the India Ocean, a strong increasing trend pattern appears on between $-10^{\circ}$ and $-30^{\circ}$ latitude. Some clues suggest that drying patch may exist in the nearby region, but this cannot be confirmed due to lacking of related data.

Figure 5 also shows that Australia and most land areas in the south hemisphere are becoming dryer; while most part of Eurasia is getting wetter, especially for the India subcontinent. However, for the strong drying signals from Yemen and Oman, and the contradictory trends over Greenland, we are investigating the original records to ensure the reliability of results.

\subsection{Long-Term Component}

The distribution of global-specific humidity follows the cosine square rule [11] [18]. This latitude pattern can be described by the following linear regression equation:

$$
S H=12.51-41.54 \cos \theta+47.08 \cos ^{2} \theta
$$

where $\theta$ is the latitude. It explains $72 \%$ variations of global-specific humidity. For temperature on land surface, this number is $95 \%$ if interactions with altitude are taken into account [18]. It seems that the water vapor distribution is more sensitive with other factors compared with temperature.

Figure 6 exhibits the global long-term component with the latitude pattern removed. It is better to be compared with Figure 2, which largely represents the humidity zonal mean that have been subtracted from longterm component. Therefore, Figure 6 essentially represents the stationary eddy structure of global humidity.

In Figure 6, regions in dark blue, like the Sahara Desert, are the driest places on the same latitude. These areas

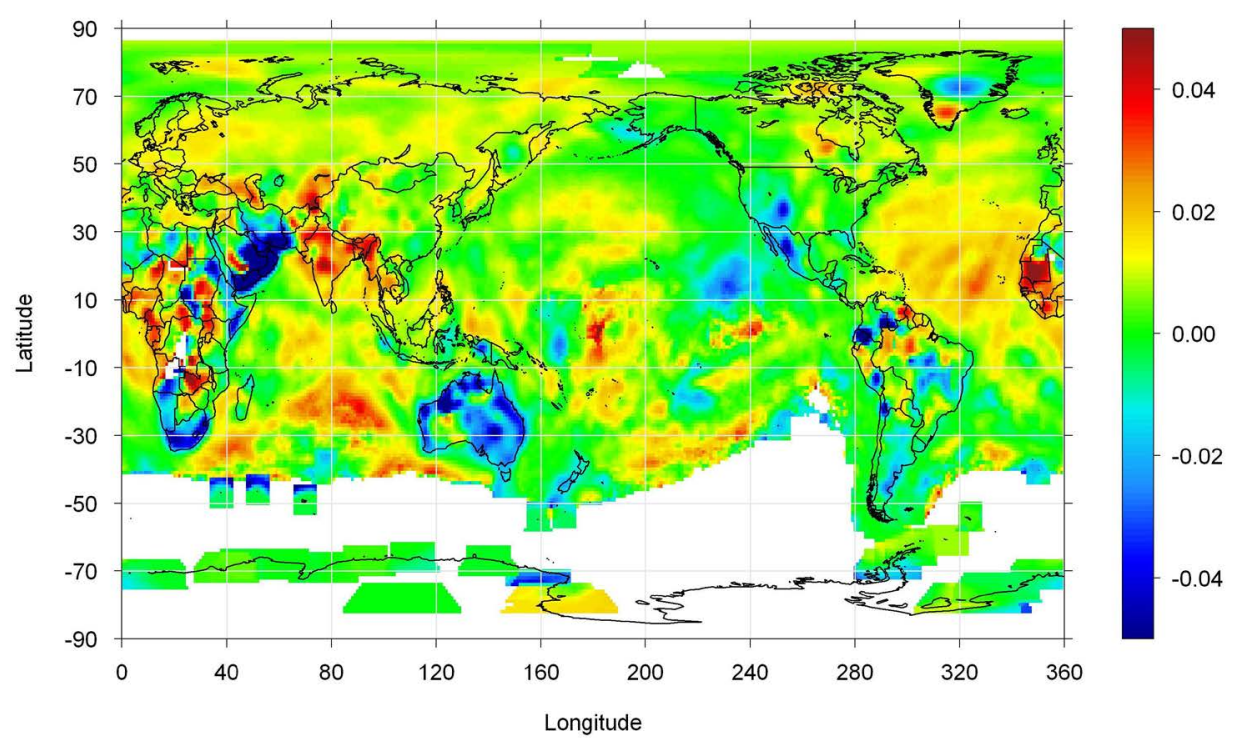

Figure 5. Specific humidity trends for the calendar year means of 1973 to 2012. Units are in g/kg/year. 


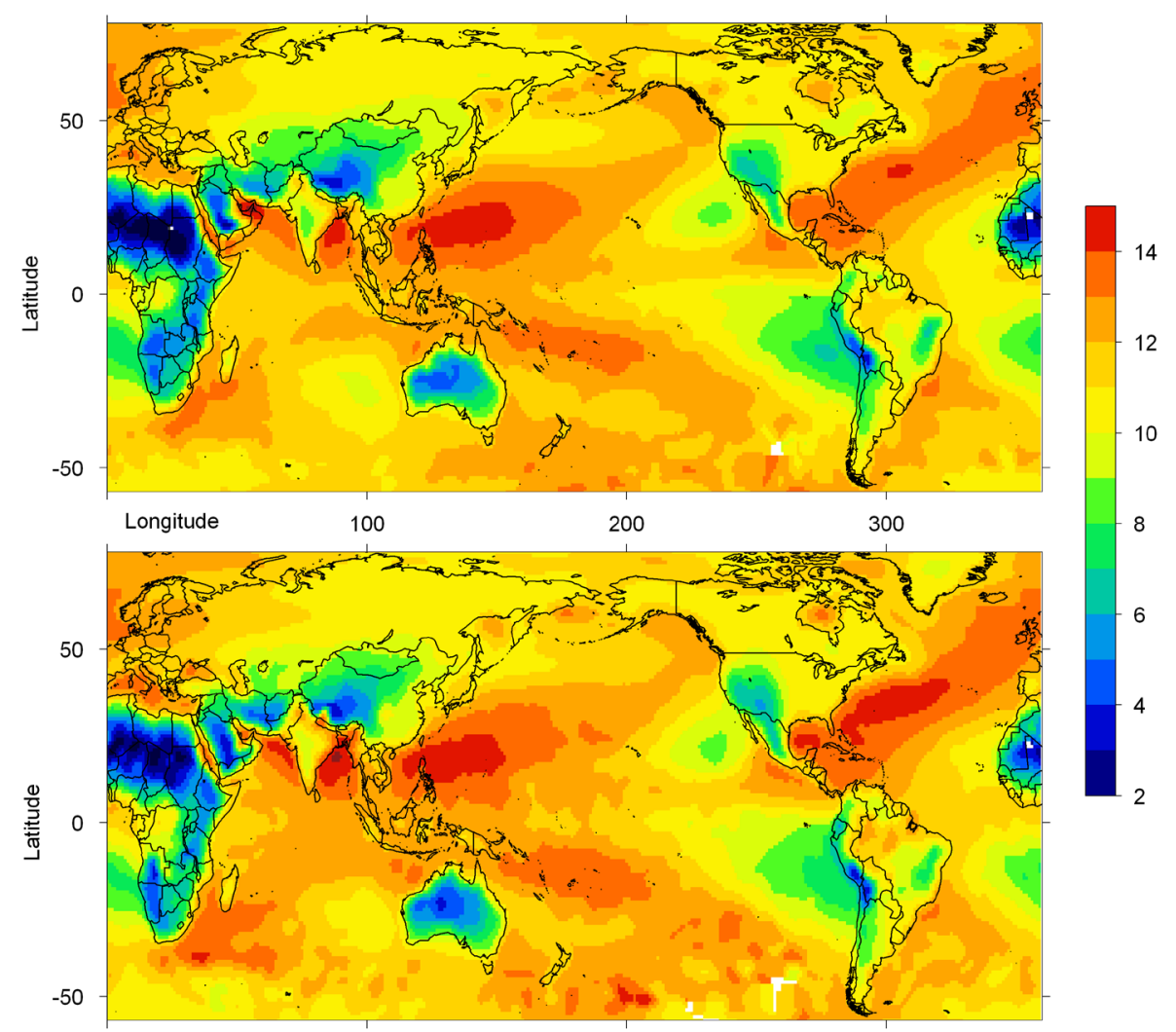

Figure 6. Snapshots of long-term component of global specific humidity on January 1976 (upper) and January 2010 (lower). Units are in g/kg.

usually are far from moisture sources, while evaporation and sun radiation are very strong. The secondary relatively dryer areas are all over oceans and marked in green color. With oceans as the moisture source, humidity levels in these regions are still below the global average. This implies that water vapors are taken out from these regions and brought into tropic or high latitudes.

Red areas with relative higher moisture content are all located on the oceans. The extra moisture either is caused by relative higher air temperature, or is transferred from other areas. In fact, in tropical latitudes, red areas are mostly on the monsoon paths or hurricane tracks; while in the mid-latitudes, they are on the tracks of mid-latitude cyclones, for example, the atmospheric-river storms; some are overlapped with high precipitation regions. They may also have relations with major ocean gyres. We believe that this kind of structures is part of the persisted water vapor circulation patterns coupled with stationary waves of air pressure and wind systems.

The movie for long-term component changes slowly with time. It confirms the findings of Figure 5 and provides extra temporal details. For example, it shows that the change of specific humidity on the Northern Atlantic Ocean mostly happened in the middle 1980s to 2000s. The movie revealed a relative humid period peaked around 1981 to 1985 for the Southwest of contiguous USA; while the humidity level decreased around 2000 and is getting worse since 2010. This can be used as the background to explain the recent ongoing drought conditions in this region. Due to its long-term prospective, the movie can be used to identify prolonged severe drought events on a large geographic scale. For example, it captured relative wet periods for Australia inland around 1973-1976 and 1997-1999, followed by a much dryer period of 2000s.

\subsection{Interannual Fluctuations in El Niño-Like Component}

El Niño-like oscillations have a smaller magnitude compared with the long-term component, but changes much faster with a complex spatial pattern. Figure 7 exhibits water vapor distribution on January 1998, which is under a strong El Niño condition. It seems that ENSO is the most dominating force for water vapor changes over the entire globe on the time scale of 2 to 6 years. In the movie of El Niño-like component, you may see changes 


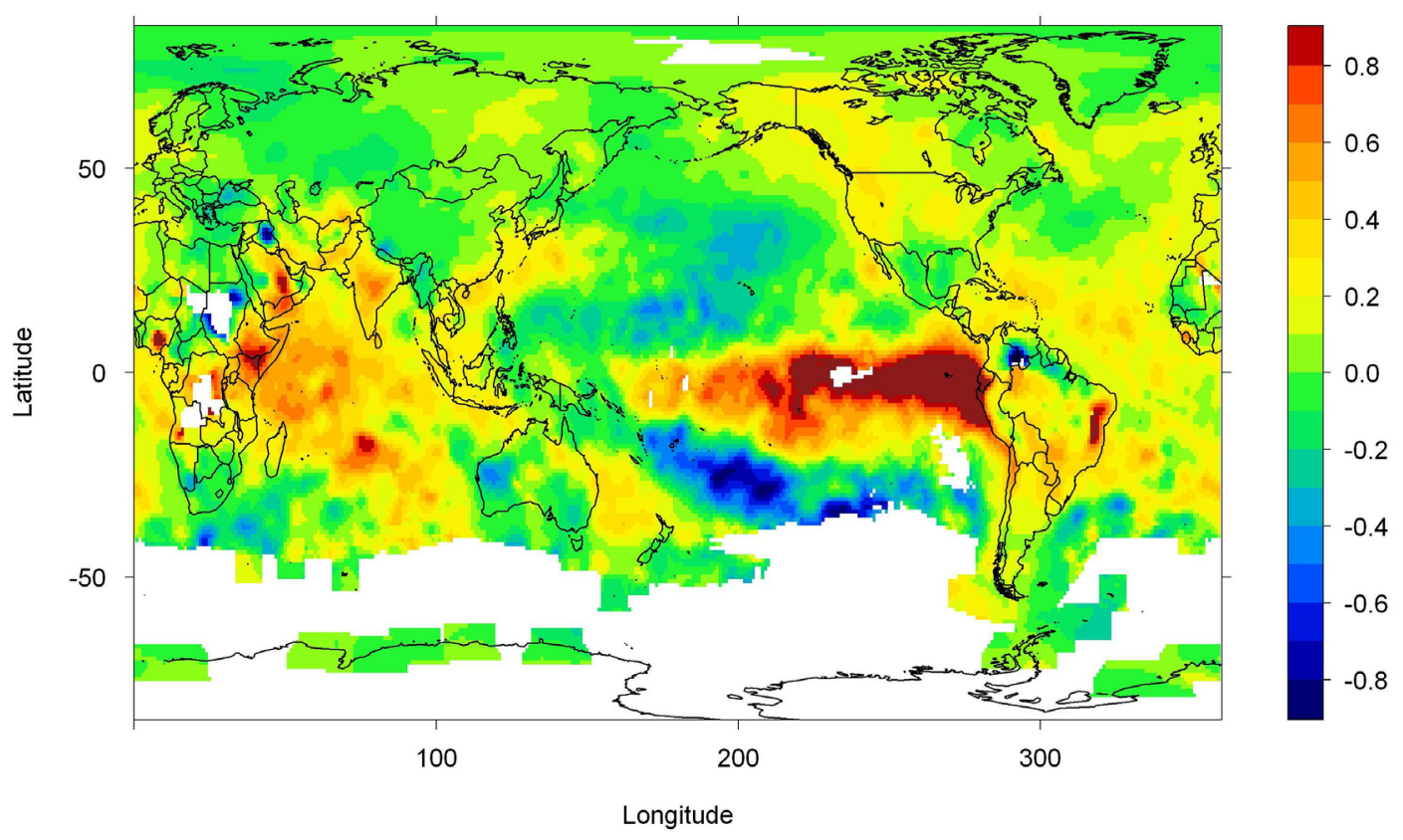

Figure 7. Snapshots of El Niño-like component of global-specific humidity (g/kg) on January 1998.

"spread out" from the equator area of the Pacific Ocean to the north and south. It implies that a large part of water vapor variations, for both oceans and lands, was forced by ENSO, or in response to the ENSO variations.

The movie of El Niño-like component changes much faster than the long-term component movie. Variations usually are transferred along a largely fixed path belonged to separated regions. These structures are very clear on Pacific-Australia, North Pacific, South Pacific, and Central Pacific areas usually are in different variation phases. On North Atlantic Ocean, fluctuations usually begin in the low latitudes near seashores of USA, and spread out to the northeast. Similar phenomena have been observed on other areas like Europe, etc. The emerged fluctuation patterns on this time scale may provide important clues for studies of regional climate change.

The spatial scales for emerged humidity variation patterns on long-term and El Niño-like component maps are larger than $20^{\circ}$ latitude or longitude $(>2200 \mathrm{~km}$ ); some extend to $6000 \mathrm{~km}$ or more. The critical range [9] for KZ filters used for spatial smoothing is $m \cdot \sqrt{k} \approx 660 \mathrm{~km}$ for areas with reasonable data density, and is close to the $5^{\circ} \times 5^{\circ}$ resolution used in HadCURH and HadISDH. This result suggests that the spatial dependency comes from the humidity movement instead of the filters, and the parameters selected for spatial smoothing are valid.

\subsection{The Problem of Marine Humidity Shift after 1982}

Some researchers believe that there is a noticeable shift in the marine humidity after 1982, most apparent in the time period of 1983 to 1987. However, the reason for the shift is not identified yet [3]. It has been speculated that it is not likely of climatic origin. Another pervasive shift is in 1998, apparently persisting until 2002.

We duplicate the spatial pattern of the 1982 shift with the difference map of long-term component of Jan. 1985 minus Jan. 1979 (Figure 8). It is consistent with the difference map of mean specific humidity 1984-1986 minus 1978-1981. The reason to use long-term component instead of original gridded data is that the previous one is more easy to use and will give spatially consistent images. In fact, 1978-1981 are El Niño "neutral" years (see Figure 4 as the agent of Niño 3.4 index), while 1984-86 contain La Niño period. Figure 8, therefore, presents a "diluted" La Niño pattern that looks like the El Nino component map of 2000. It clearly suggests that the shift of marine humidity after 1982, although the behind mechanism could be more complicated, is still in the category of changes caused by climatic variations around this time period.

The shift after 1998, which spatial pattern is not presented here, looks very similar with the 1982 shift. However, the global average humidity level after 1998 varied in a different direction compared with 1982 shift that under a similar La Niño condition. This situation could not be explained by the association with ENSO, but it is still natural origin. High-resolution maps of the changes may lead us to the right research questions. 


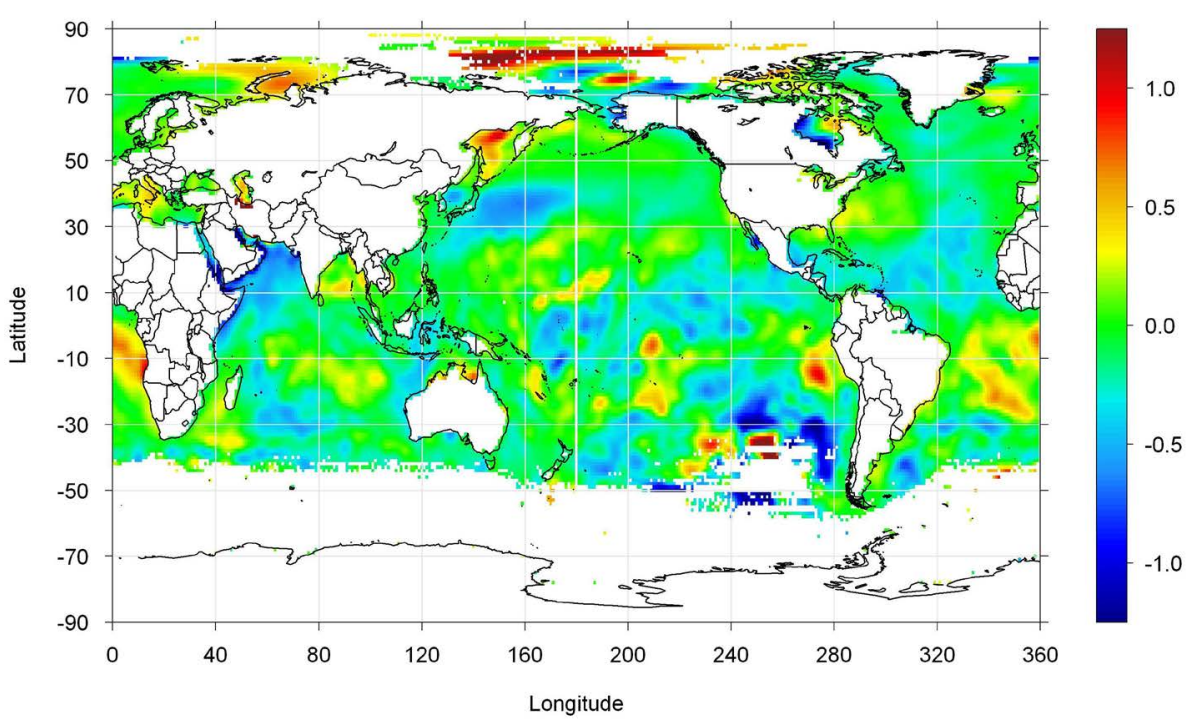

Figure 8. Difference map of SH long-term component of Jan. 1985 minus Jan. 1979. Units are in $\mathrm{g} / \mathrm{kg}$.

\section{Discussion}

Previous sections had described the process to create the high-resolution global true value humidity database covered both lands and oceans, and how to reconstruct the long-term trend and El Niño-like component. For gridded humidity data, our work essentially is the extension of HadCURH and HadISDH [3] [4]. In these two databases, each grid value is the mean of all observations in the $5^{\circ} \times 5^{\circ}$ box and the same time period; while in our work it is the weighted-mean based on asymptotically Gaussian distributed kernel [9] with critical region of $6^{\circ} \times 6^{\circ}$. Theoretically, their accuracies are comparable. However, the resolution of our database is much higher. The further step of separating fluctuations on different time scales simplifies the pictures of humidity movements. These two features make our database more suitable for detecting spatial and temporal patterns of humidity variations via visualization.

In current stage, we skipped the step of homogenization in creating the humidity database. This is usually a necessary step for any analysis of long-term trends and variability. However, it has been found that the effects of homogenization on specific humidity are small and could be neglected [4]. For current study purposes, our database gives consistent results as homogenized data. The reason, we speculate, is partly because the related variables and statistics are robust and not sensitive to extreme values. Moreover, the errors in the observation data were suppressed in KZ filters' output. The separation of signals with the background noise via KZ method provides us the base for satisfied analyses accuracy.

The interpretation of the spatial patterns of humidity variations is an interesting topic. It is well known that moisture convergence in the tropics is dominated by the transport provided by the mean meridional circulation, also known as Hadley Cells in the tropics latitudes. The subtropics serve as its water vapor source region. From subtropics to polar areas, the midlatitude eddy takes over and dominates the moisture transport [1] [22]. Eddies can be characterized as diffusion processes in vary scales that arise from horizontal temperature and humidity gradients [23]. Eddy carried moisture transports mostly are poleward in the meridional direction, removing water from the tropics or subtropics and supply it to middle and high latitudes. Transient eddies have typical time scale of 7 - 10 days, therefore are not easy to be described with climate data directly. However, we can manage to capture their mean meridional transport pattern with plots of the long-term component as showed in Figure 6.

The major wind fields are eastward in the middle latitudes and westward in the tropics [21], due to the permanent dynamic winds caused by Coriolis forces and astronomic gravities [8] [24]. Long-term component emphasizes the abnormal on the meridional direction, reflecting the stationary moisture eddy. As discussed in Section 4.2, given the wind directions and moisture distribution in related region, the red areas in Figure 6 are not just for relative high moisture content; they are dynamic channels that transport water vapor on the surface. Interannual variations in El Niño scale (as illustrated in Figure 7) may enhance or calm down those patterns. 
The long-term sea-level pressure climate around North America, as showed in Figure 9, could explain the moisture channels on long-term scale in this region. These semi-permanent atmospheric pressure centers, i.e., North Pacific High and Aleutian Low, Bermuda-Azores High and Icelandic Low, decide the wind field and the heat/moisture flux of this region. These structures are stronger in the winter than in the summer, transporting warm/humid air poleward and upward and cold/dry air equatorward and downward. The poleward movements will be speeded up by the Coriolis forces and turned to west, finally form the winds paralleled to the contour lines between the high and low air pressure centrals. Therefore, coupled with latitude gradients, the ocean-land divergences for temperature and humidity (as illustrated in Figure 10), and the deflection caused by Coriolis acceleration, these air pressure systems perfectly explain the humidity stationary eddies on North Pacific and North Atlantic (see Figure 6).

These air pressure systems also contribute for creation of the jet stream systems crossed the North America Continent. Seasonal oscillations of their locations and strengths create tendency of diving pattern of these jet streams and contribute to multiple synoptic problems. In fact, the orientation of the polar jet stream in the upper troposphere controls the mid-latitude cyclones that caused massive energy and moisture exchanges in this region, which is an important synoptic mechanism for the long-term moisture transport pattern.

From the maps of long-term humidity component, the moisture reeduce up to 20 units over oceans in the meridional direction, which is about $2 \%$ reduction in air mass, obviously contribute to the reduction of long term pressure in the same directions noticeably more than $1 \%$. That effect is mostly absent over North America continent and inevitably causes diving pattern in Jet Streams.

Both Figure 5 and the movie of the long-term component maps illustrate that the specific humidity levels of the Northern Atlantic Ocean surface is increased in the past decades, and this is the most significant regional change with consistent spatial pattern. Meanwhile, the moisture levels over contiguous USA are reducing in the recent decade, especially for the western areas. The enlarged divergence of moisture levels over USA and nearby oceans reflects enhanced long-term moisture transports, inevitably affect the diving patterns of jet stream and contribute to regional weather. The fluctuations in the eastward air currents crossed the Northern America Continent may cause different synoptic conditions for the east and west regions, and worth further investigation.

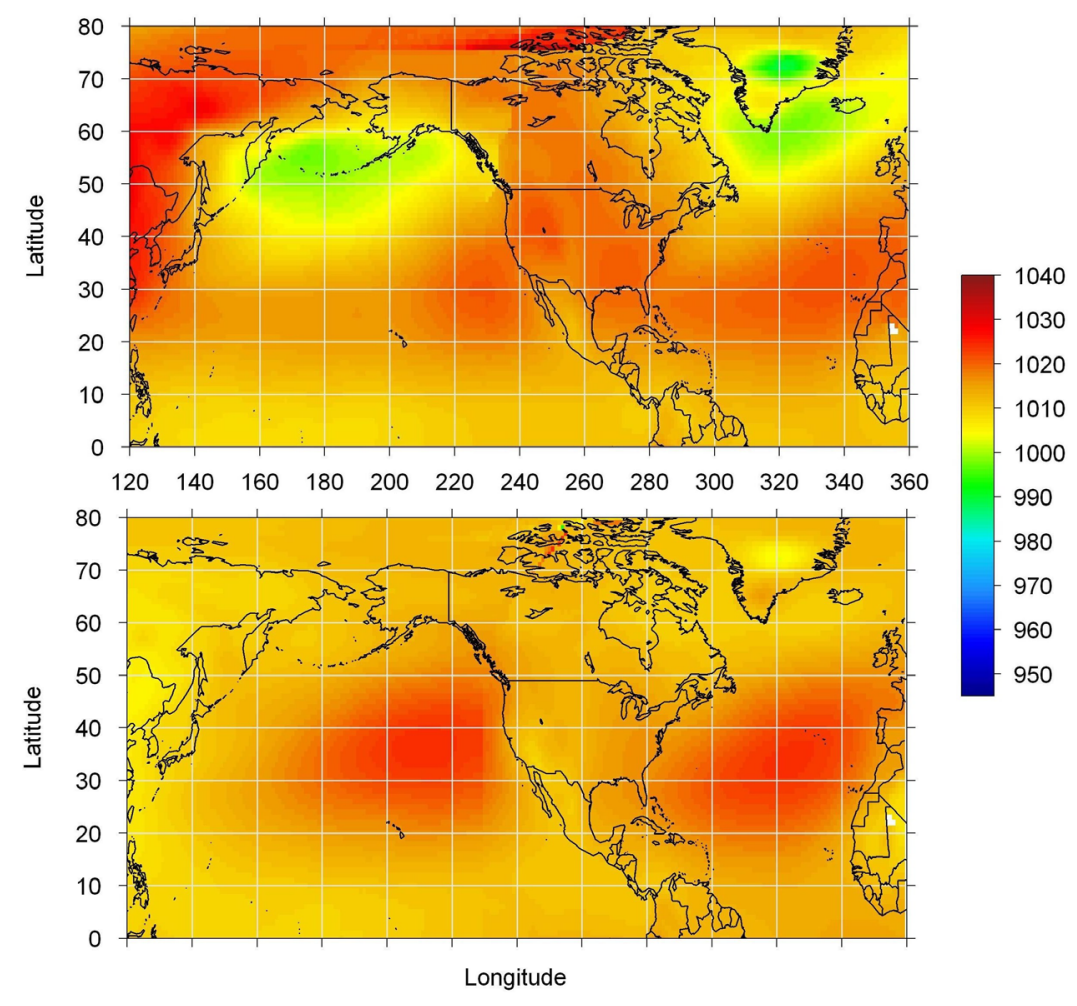

Figure 9. Long-term sea-level pressure (mbar) for winter (top) and summer (bottom) around North America. 


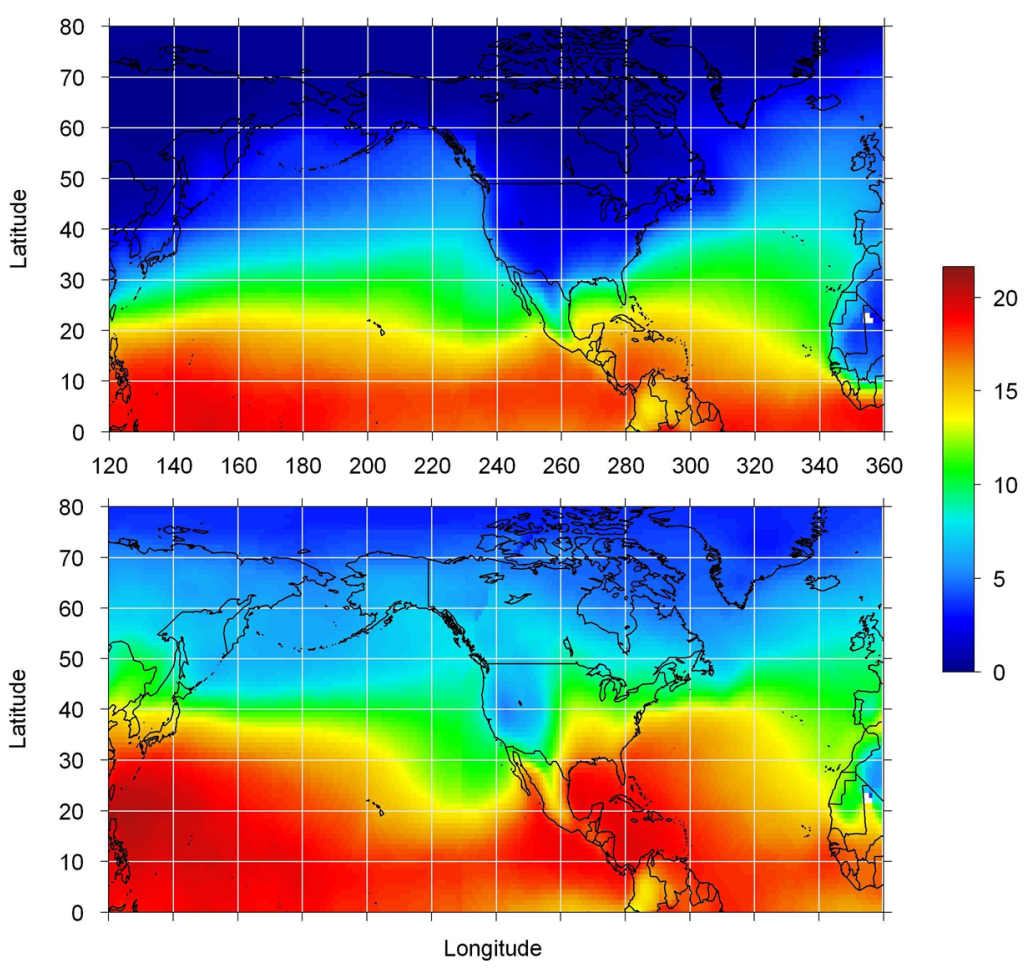

Figure 10. Long-term specific humidity (g/kg) for winter (top) and summer (bottom) around North America.

The temperature changes around India are relative small [12] [18]; therefore, the significant increased humidity levels in Figure 5 over this region are more related with the Asian summer monsoon. It seems that the northward flows from the Southern Hemisphere subtropics in the Somalian Jet are bringing more precipitations into India and Southeast Asia during the summer in recent decades. This trend will directly affect the weather of this area.

Water vapor is considered as major source of dynamics in atmospheric processes. Tropical area is receiving major part of sun radiation and is working as essential vapor generator over planet (see Figure 2). That permanent generation of extra mass in tropical atmosphere causes tropical air mass expansion and transmission of air to higher latitudes in North and South directions. That transport to the cold North is causing extra precipitations with essential shrinkage of vapor and further contributing to air mass transport to higher latitudes. Proportion of vapor mass at tropics is about $2 \%$ higher than at higher latitudes, that cause approximately the same drop in air pressure (see Figure 9 and Figure 10). Permanently existed drop in air pressure is actually causing transport of air mass to higher latitudes. In mid latitudes those transmissions will be knocked out to the East by rapidly increasing Carioles force. This effect is causing strong atmospheric current at mid-latitudes in the East direction (jet stream). Carioles coefficient at mid-range latitudes may cause up to $30 \%$ increase of speed of mass transferred from tropical side. Transferring of mass from low altitudes to high altitudes due to convectional forces may cause only less than $1 \%$ change. Still latitude transfer can be applicable only to long time scales when altitude transfer affect short synoptic scales.

Figure 2 display elevated levels of water vapor concentrations along longitudes on west side of the Pacific and Atlantic oceans what cause uneven air transport to higher latitudes. Those uneven levels along the tropics have been created by equatorial trade winds in the west direction. Trade winds can be explained by astronomic forces and rotation of the Earth in East direction [24].

West trade winds, strong expansion to the North at the west of Pacific, eastward jet stream in higher latitudes are creating clockwise circulation in Northern hemisphere in Pacific and similar at Atlantic oceans. North American continent is facing downwards transport at the west coast of cold and dry air, and upwards transport of warm and humid air at Atlantic. This effect is enhancing by very low vapor transport to the North over continental areas of Mexico. This will cause fluctuation of eastwards jet stream current to the South over American 
continent and enhance strong mechanism of energy exchange between South and North. During last couple decades we could observe enhancing of that mechanism (Figure 6). That was causing essential drought at the West United States, violent weathers at South and Northeastern. Strong buildup of moist at North Atlantic in last few decades is enhancing all those long term patterns. It is essentially contributing to wider ranges of most of atmospheric variables and frequencies of extreme events. Wider range of changes is causing essentially more problems rather then little changes of the means.

\section{Summary}

In this paper, we demonstrated the usefulness of our high-resolution near-global specific humidity database for both gridded data and reconstructed long-term and interannual components. The change of the spatial pattern of the long-term component is informative for long-term forecasting, while the El Niño-like component may provide us inspiration to look into the dynamic mechanism of global and regional humidity changes. As the key technical method used in creation of the database, $\mathrm{KZ}$ filters enable us to separate out the high resolution data with satisfied accuracy, and therefore make this database suitable for exploring global water vapor movement in spatio-temporal dimensions via visualization.

\section{Acknowledgements}

The authors would like to thank Dr. Robert Henry from New York State Department of Environmental Conservation for the help on humidity data preparation and analysis.

\section{References}

[1] Saha, K. (2008) The Earth’s Atmosphere: Its Physics and Dynamics. Springer-Verlag, Berlin Heidelberg.

[2] Bridgman, H. and Oliver, J. (2006) The Global Climate System: Patterns, Processes, and Teleconnections. Cambridge University Press, Cambridge. http://dx.doi.org/10.1017/CBO9780511817984

[3] Willett, K., Dunn, R., Thorne, P., Bell, S., de Podesta, M., Parker, D., Jones, P. and Williams Jr., C. (2014) HadISDH Land Surface Multi-Variable Humidity and Temperature Record for Climate Monitoring. Climate of the Past, 10, 1983-2006. http://dx.doi.org/10.5194/cp-10-1983-2014

[4] Willett, K., Jones, P., Gillett, N. and Thorne, P. (2008) Recent Changes in Surface Humidity: Development of the HadCRUH Dataset. Journal of Climate, 21, 5364-5383. http://dx.doi.org/10.1175/2008JCLI2274.1

[5] Amenu, G. and Praveen, K. (2005) NVAP and Reanalysis-2 Global Precipitable Water Products: Intercomparison and Ariability Studies. Bulletin of the American Meteorological Society, 86, 245-256. http://dx.doi.org/10.1175/BAMS-86-2-245

[6] Dessler, A. and Davis, S. (2010) Trends in Tropospheric Humidity from Reanalysis Systems. Journal of Geophysical Research, 115, D19127. http://dx.doi.org/10.1029/2010jd014192

[7] Haar, V., Bytheway, J. and Forsythe, J. (2012) Weather and Climate Analyses Using Improved Global Water Vapor Observations. Geophysical Research Letter, 39, L15802.

[8] Zurbenko, I. and Potrzeba, A. (2013) Periods of Excess Energy in Extreme Weather Events. Journal of Climatology, 2013, Article ID: 410898. http://dx.doi.org/10.1155/2013/410898

[9] Yang, W. and Zurbenko, I. (2010) Kolmogorov-Zurbenko Filters. WIREs Computational Statistics, 2, 340-351. http://dx.doi.org/10.1002/wics.71

[10] Wikipedia (2015) Kolmogorov-Zurbenko Filter. http://en.wikipedia.org/wiki/Kolmogorov\%E2\%80\%93Zurbenko_filter

[11] Zurbenko, I. and Cyr, D. (2011) Climate Fluctuations in Time and Space. Climate Research, 46, 67-76. http://dx.doi.org/10.3354/cr00956

[12] Zurbenko, I. and Luo, M. (2012) Restoration of Time-Spatial Scales in Global Temperature Data. American Journal of Climate Change, 1, 154-163. http://dx.doi.org/10.4236/ajcc.2012.13013

[13] National Climatic Data Center (2009) International Comprehensive Ocean-Atmosphere Data Set (ICOADS) Release 2.5, Monthly Summaries. Updated Monthly at http://dx.doi.org/10.5065/D6CF9N3F

[14] Adam, S., Lott, N. and Vose, R. (2011) The Integrated Surface Database: Recent Developments and Partnerships. Bulletin of the American Meteorological Society, 92, 704-708. http://dx.doi.org/10.1175/2011BAMS3015.1

[15] Dai, A. (2006) Recent Climatology, Variability, and Trends in Global Surface Humidity. Journal of Climate, 19, 3589- 
3606. http://dx.doi.org/10.1175/JCLI3816.1

[16] Williams, C.N., Menne, M.J. and Thorne, P.W. (2012) Benchmarking the Performance of Pairwise Homogenization of Surface Temperatures in the United States. Journal of Geophysical Research, 117, Article ID: D05116. http://dx.doi.org/10.1029/2011jd016761

[17] Letestu, S. (1966) International Meteorological Tables. WMO-No.188.TP.94, World Meteor Organization, Geneva.

[18] Luo, M. and Zurbenko, I. (2012) Comparison of Time and Spatial Scales in Global Temperature Data. In: JSM Proceedings 2012, Section on Statistics and Environment, American Statistical Association, Alexandria, 3040-3051.

[19] Zurbenko, I. (1986) The Spectral Analysis of Time Series, North-Holland Series in Statistics and Probability. Elsevier, Amsterdam.

[20] Dahlman, L. (2009) Climate Variability: Oceanic Niño Index. Climate Watch Magazine, 30 August 2009.

[21] Lanzante, J.R. (1996) Resistant, Robust and Non-Parametric Techniques for the Analysis of Climate Data: Theory and Examples, including Applications to Historical Radiosonde Station Data. International Journal of Climatology, 16, 1197-1226. http://dx.doi.org/10.1002/(SICI)1097-0088(199611)16:11<1197::AID-JOC89>3.0.CO;2-L

[22] Trenberth, K. and Guillemot, C. (1998) Evaluation of the Atmospheric Moisture and Hydrological Cycle in the NCEP/ NCAR Reanalyses. Climate Dynamics, 14, 213-231. http://dx.doi.org/10.1007/s003820050219

[23] Barry, L., Craig, G. and Thuburn, J. (2002) Poleward Heat Transport by the Atmospheric Heat Engine. Nature, 415, 774-777. http://dx.doi.org/10.1038/415774a

[24] Zurbenko, I. and Potrzeba-Macrina, A. (2013) Tides in the Atmosphere. Air Quality, Atmosphere, \& Heath, 6, 39-46. http://dx.doi.org/10.1007/s11869-011-0143-6 